\title{
POR QUE ELE? REFLEXÕES SOBRE O PERCURSO E OS BASTIDORES DE UMA BIOGRAFIA HISTÓRICA
}

\author{
ÉDER DA SILVA SILVEIRA \\ Universidade de Santa Cruz do Sul
}

RESUMO O artigo tem como objetivo apresentar alguns apontamentos e reflexões sobre os bastidores e os principais desafios encontrados pelo autor na pesquisa que resultou em uma biografia de Manoel Jover Teles. 0 texto está dividido em dois principais blocos. No primeiro, são discutidas as possiveis formas e as peculiaridades de uma biografia escrita na perspectiva de uma pesquisa histórica. No segundo, reflete-se sobre algumas possibilidades de relação entre a biografia histórica e a micro-história italiana e aponta-se para algumas informações sobre os desafios colocados à pesquisa biográfica em relação ao acesso de arquivos e fontes. Trata-se de um texto ensaístico e de cunho bibliográfico que, dentre outras questões, defende e argumenta que a biografia realizada por historiadores, seja no campo da História ou na área da história da educação, deve associar narração e explicação, sem deixar de colocar atenção às peculiaridades do corpus documental.

Palavras-chave: Biografia histórica. Manoel Jover Teles. Micro-história.

WHY HIM? REFLECTIONS ON THE COURSE AND

\section{BEHIND THE SCENES OF A HISTORICAL BIOGRAPHY}

The article aims to present some notes and reflections on the sidelines and main challenges encountered by the author in his research which resulted in a biographical thesis on Manoel Jover Teles. The text is divided into two main blocks. At first, it discusses the possible ways and the peculiarities of a biography written in the perspective of historical research. In the second, reflects on some possibilities of relationship between historical biography and Italian history, pointing out some information about the challenges posed to biographical research in relation to access files and sources. This is an essayistic and bibliographic text that, among other issues, defends and argues that the biography held by historians, whether in the field of History, or in the area of the history of education, must associate narration and explanation, being attentive to the peculiarities of its documentary corpus.

Keywords: Historical Biography. Manoel Jover Teles. Micro-history. 


\section{RESUMEN ¿PORQUE ÉL? REFLEXIONES SOBRE EL CURSO Y LOS BASTIDORES DE UNA BIOGRAFÍA HISTÓRICA}

El artículo tiene como objetivo presentar algunas notas y reflexiones sobre los bastidores y las principales dificultades encontradas por el autor en la investigación que dio lugar a una tesis biográfica sobre Manuel Jover Teles. El texto se divide en dos grandes bloques. En el primero se discuten las posibles formas y peculiaridades de una biografia escrita desde la perspectiva de la investigación histórica. En el segundo se refleja una posible relación entre la biografia histórica y la micro-historia italiana, señalando alguna información sobre los desafios que enfrenta la investigación biográfica en relación con el acceso a los archivos y fuentes. Es un texto ensayístico y de naturaleza bibliográfica que, entre otras cuestiones, argumenta y sostiene que la biografia hecha por los historiadores, ya sea en el campo de la historiae como en el de la historia de la educación, debe asociar la narración y la explicación así como escuchar las peculiaridades de su corpus documental.

Palabras clave: Biografía histórica. Jover Telles Manoel. Microhistoria.

\section{Introdução}

No segundo semestre do ano de 2000, como aluno do curso de Licenciatura em História, tive a oportunidade de desenvolver e apresentar um trabalho intitulado "Ensaios de pesquisa de campo em Arroio dos Ratos", em uma disciplina de Antropologia. Naquela ocasião, a escolha por Arroio dos Ratos, no Estado do Rio Grande do Sul, era facilmente compreensivel. Tratava-se do município onde eu residia e, sobretudo, do local onde funcionou a primeira usina termelétrica do país, berço da indústria carbonífera nacional. Na comunidade de Arroio dos Ratos, habitavam muitos ex-mineiros que haviam trabalhado tanto na superfície como no subsolo das minas de carvão. Era, portanto, uma comunidade potencial para realizar o exercício de campo do trabalho final que havia sido solicitado. Na época, ainda era forte a tendência de trabalhar com a categoria "cotidiano" associada ao "mundo do trabalho". E, nesta perspectiva, busquei visitar e conviver com alguns mineiros, realizando uma série de entrevistas a partir da metodologia da história oral. O trabalho foi apresentado na semana acadêmica do curso de História da universidade e, posteriormente, recebeu mérito de distinção. A situação rendeu-me duas bolsas de iniciação científica até o final da graduação, inserindo-me efetivamente no mundo da pesquisa acadêmica, em espaços que ultrapassavam os limites da sala de aula.

A experiência com a pesquisa na graduação foi fundamental em minha formação, influenciando-me nas futuras escolhas e caminhos trilhados no mestrado e doutorado. Em 2004, fui selecionado para participar como expositor nas Primeras Jornadas del Mercosur y Segundas Bonaerenses sobre Patrimonio Cultural y Vida Cotidiana, em Buenos Aires, onde apresentei uma comunicação intitulada "O Cotidiano nas Minas de Carvão de Arroio dos Ratos (1924-1956)", baseado, sobretudo, em icono- 
grafia e fontes orais. Foi naquela oportunidade que percebi, nas entrevistas, referências a um mineiro de subsolo conhecido como "Manolo, o comunista", que fora deputado, líder sindical, e que havia estado na União Soviética. As informações sobre Manolo (Manoel Jover Teles) eram poucas e surgiam sutilmente em algumas entrevistas. Naquele momento, meu olhar estava direcionado para o cotidiano daqueles trabalhadores e minha imaturidade acadêmica também não permitia que eu fosse sensivel a questões relativas à biografia. Apenas em 2008, depois de concluído o mestrado, ao revisar as entrevistas realizadas na época da graduação, consegui enxergar o que antes não vira: a existência de um operário cuja trajetória de vida havia extrapolado questões locais e regionais e que, envolta em mistérios e indagações diversas, poderia possibilitar a produção de um conhecimento histórico através de um caminho não apenas atrativo, mas totalmente desafiador: a biografia.

A proposição de um projeto de pesquisa de caráter biográfico foi aceita e resultou na tese de doutorado intitulada "Além da Traição: Manoel Jover Teles e o comunismo no Brasil do século XX", defendida em 2013. Passados três anos da defesa, ao revisitar o texto para a sua publicação em livro, ${ }^{1}$ percebo o quanto de seu percurso e contexto de produção ficaram eclipsados na redação produzida entre 2009 e 2013. É dessa percepção, aliada à motivação encontrada em alguns colegas que me incentivaram a dar visibilidade aos bastidores dessa biografia, que nasce o presente artigo.

\section{Qual modelo biográfico? Manolo e a biografia histórica}

Com quase um ano de idade, em 1921, o paulis-

1 O livro foi lançado pela Paco Editorial, sob o seguinte título: Por que ele? Educação, traição e dissidência comunista na trajetória de Manoel Jover Teles, o "Manolo". (SILVEIRA, 2016) ta Manoel Jover Teles chegou ao Rio Grande do Sul com sua família. Trabalhou nas minas de carvão de São Jerônimo, ${ }^{2}$ desde os onze anos de idade, no local onde funcionou a primeira usina termelétrica do Brasil, denominado "Poço Um", hoje Museu Estadual do Carvão. Tanto no subterrâneo das galerias das minas de carvão, como em outros cenários da antiga usina, o jovem Manolo, como seria conhecido, desempenhou diferentes tarefas. Residiu em Arroio dos Ratos até meados da década de 1940, onde atuou no meio sindical e, também, como membro do Partido Comunista Brasileiro (PCB), foi deputado estadual do Rio Grande do Sul no ano de 1947.

Em virtude das cassações impostas durante o governo Dutra, Manoel Jover Teles deixou a Assembleia Legislativa como deputado do PCB e foi para o Rio de Janeiro, onde intensificou sua militância no Partido Comunista. Seu destaque como militante fez com que passasse a representar o Partido dentro e fora do país. Foi um dos brasileiros que integrou a segunda turma em uma "Escola de formação de Quadros" de Moscou, na URSS, e esteve na China e em Cuba, buscando instrumentalização para uma "revolução" no Brasil.

Manoel Jover Teles tinha o hábito de escrever suas palestras e alguns discursos. Dentre sua produção, destaca-se a triologia Café Amargo, que se encontra em poder de um familiar, que não me permitiu o acesso a tais obras para a pesquisa. Jover também escreveu diversas poesias, manuscritos e o livro $\mathrm{O}$ movimento sindical no Brasil, publicado pela Editora Vitória, em 1962 (1a edição), e pela Livraria Editora Ciências Humanas, em 1981 (2ª edição). Além disso, foi dirigente e jornalista do PCB, e escreveu artigos para os jornais Voz Operária (1958/59) e Novos Rumos (1959/61).

2 A região onde se estabeleceram, hoje, é o município de Arroio dos Ratos que, na época, pertencia à cidade de São Jerônimo como "vila". A emancipação de Arroio dos Ratos ocorreu em dezembro de 1964. 
No contexto da cisão que ocorreu no PCB, em 1962, Jover Teles, juntamente com Jacob Gorender, foi um dos responsáveis pela organização do Partido Comunista Brasileiro Revolucionário - PCBR -, a favor da luta armada, passando, logo em seguida, a integrar as fileiras do $\mathrm{PC}$ do $\mathrm{B}$.

No final da década de 1970, o PC do B acusou Manoel Jover Teles de ter cooperado com a "repressão" para a neutralização do "Aparelho da Lapa", no episódio que ficaria conhecido como a "Chacina da Lapa", em São Paulo. Em um congresso do Partido, em fevereiro de 1983, mais de seis anos depois dos acontecimentos da Lapa, foi aprovado um relatório culpando-o pelos acontecimentos de então. 0 documento o considerou um traidor.

Com as dificuldades enfrentadas pelo estigma da traição, Jover passou a viver escondendo-se da imprensa que o rotulava de "traidor". Encontrou sossego em Florianópolis, Santa Catarina, onde viveu os últimos anos de sua vida como escritor, integrando o Grupo de Poetas Livres daquele Estado e se tornando um membro da Academia Catarinense de Letras e Artes, ocupando a cadeira de no 11. Faleceu em junho de 2007, deixando várias memórias e uma trajetória de vida ocultada pelo estigma da traição.

As dúvidas iniciais quanto à pesquisa sobre Manoel Jover Teles eram quanto ao tipo de biografia que iria construir e por que realizá -la. Esses questionamentos me encaminharam para muitas leituras sobre biografia, no intuito de me aproximar das sugestões dos autores que trabalhavam com o tema e/ou realizavam reflexões sobre o gênero biográfico, ${ }^{3}$ buscando encontrar um modelo ideal de biografia para analisar e escrever sua trajetória. A saga por essa busca foi longa e deveras cansativa e permitiu perceber que, de certa forma, havia na literatura algum esforço para tipificar a pes-

3 Schmidt (2000a; 2000b; 2009), Borges (2004; 2006), Bourdieu (1996), Dosse (2009), Del Priore (2009), Levi (2008), Loriga (1998; 2011) e Le Goff (1989). quisa biográfica.

Philippe Lejeune (2005), que se destacou no exercício do estabelecimento de bases teóricas sobre o gênero (auto)biográfico, percebia que uma biografia poderia ser dividida em três categorias principais: a "biografia pura", "o testemunho com pretensão de biografia" e o "testemunho puro". o parâmetro que basicamente incidia sobre essa classificação era o fato do pesquisador conhecer ou não o sujeito a biografar. No primeiro tipo, o historiador não conhece o biografado e busca instrumentalizar-se através da diversidade de documentos e testemunhos. Nos demais, o pesquisador conhece o sujeito que será biografado e o que os diferencia é o fato de que no "testemunho puro" o biógrafo participou de momentos da vida do biografado.

A obra La biographie, de Daniel Madelénat (1984), propunha pensar o gênero biográfico segundo três paradigmas: a biografia clássica, a romântica e a moderna. Em caminho semelhante e em um texto de grande fôlego, François Dosse distinguiu três modalidades da abordagem biográfica: a idade heroica, a idade modal e, por fim, a idade hermenêutica. Segundo ele, "os três tipos de tratamento da biografia podem combinar-se e aparecer no curso de um mesmo período" (DOSSE, 2009, p. 13).

Para Giovanni Levi, os principais tipos de biografia são: "prosopografia \& biografia modal", "biografia \& contexto", "biografia \& hermenêutica" e "biografia \& caso extremo". De acordo com Levi, as biografias de casos extremos "são usadas especificamente para esclarecer o contexto". Nesse caso, "o contexto não é percebido em sua integridade e exaustividade estáticas, mas por meio de suas margens do campo social" (LEVI, 2008. p. 176). Um exemplo, nesse sentido, é a biografia de Menocchio, em "O queijo e os vermes", de Carlo Ginzburg (2006), onde o autor analisa a cultura popular através de um caso extremo. 
Antes de realizar as disciplinas do curso de Doutorado e de aprofundar o estudo sobre a literatura a respeito do gênero biográfico, pensava que minha proposta de investigação seria a de examinar a história do movimento sindical e do comunismo no Brasil, durante o primeiro período de experiência democrática da República brasileira (1945-1964), tendo como fio condutor a história de vida de Manoel Jover Teles. Os receios e a falta de clareza sobre algumas questões teóricas e metodológicas refletiram-se, assim, na primeira versão do projeto de pesquisa que se intitulou "Das minas para a história: uma análise do movimento sindical e do comunismo no Brasil a partir da biografia e bibliografia de Manoel Jover Teles". Acreditava que trabalharia com o "personagem" Jover Teles enquadrando-o entre o que Giovanni Levi (2008) chamou de "biografia \& contexto" e "caso extremo". Essa percepção, no entanto, foi alterada à medida que avancei com as leituras realizadas nas disciplinas do curso, bem como durante o levantamento, a leitura e a análise de parte das fontes. Outro fator fundamental, naquele momento, foi questionar-me sobre as especificidades de uma biografia realizada por um historiador, bem como as relações entre biografia e historiografia. Era preciso ter mais clareza sobre quais eram as funções e característica da pesquisa histórica e não perdê-la de vista. Nesse sentido, a leitura da obra Em busca da Terra da promissão..., de Benito Schmidt (2004), bem como de outros textos de caráter teórico-metodológico, de autoria desse historiador ou organizados por ele, foram fundamentais para compreender os atributos de uma biografia realizada no campo histórico.

Uma das principais funções da pesquisa histórica, esteja ela no campo da História ou da História da Educação, é fornecer explicações. Explicações aos sujeitos, à sociedade, às instituições diversas, às próprias indagações ou problematizações do pesquisador em relação ao seu objeto de estudo. 0 objeto de estudo em uma "biografia científica" ${ }^{4}$ pode variar de acordo com o tipo de história de vida que se pretende realizar. ${ }^{5}$ Como vimos, alvo de esforço de sistematização e classificação de alguns autores, a biografia, a rigor, tem como principal objeto de estudo a própria vida do indivíduo biografado. No entanto, trata-se de um objeto que pode se metamorfosear de acordo com os objetivos do pesquisador e do tipo de biografia elegida. É nesta perspectiva que encontrei respostas quando me perguntei qual o sentido da biografia de Jover Teles. Como observou Vavy Pacheco Borges, em relação à biografia de Gabrielle Brune-Sieler, ao pensar um sujeito, pensa-se nas normas, nas práticas, nas regras da sociedade e da família em que ele estava inserido (BORGES, 2004, p. 301). Assim, "a razão mais evidente para se ler uma biografia é saber sobre uma pessoa, mas também sobre a época, sobre a sociedade em que ela viveu" (BORGES, 2006, p. 215). Percebi, então, que se trabalhasse com a biografia apenas como um "fio condutor", perderia o foco no indivíduo Jover Teles e correria o risco de me afastar de um método biográfico pautado na articulação de uma história-narrativa a uma história-problema. Foi preciso compreender que "a biografia histórica é antes de tudo história" e que "ela precisa se pautar pelos procedimentos de pesquisa e pela própria narrativa deste campo de conhecimento que se propõe a explicar e/ou compreender o passado" (SCHMIDT, 2011).

$\mathrm{Na}$ "adequação entre uma figura singular, por um lado, e um meio e uma época, por outro" (DOSSE, 2009, p. 219), equivoquei-me na

4 "A biografia dita 'científica' ou 'literária", conforme apresentou Vavy Pacheco Borges, é aquela "com preferência narrativa e finalidade histórica, que trabalha com documentação numerosa e variada". (BORGES, 2006, p. 213)

5 Não é nossa intenção tratar como sinônimos os termos biografia e história de vida, assim como biografia e trajetória. Existe ampla literatura sobre essa questão e, abordá-la, exigiria muita digressão e abdicar do escopo desse artigo. 
busca de um "modelo" de biografia para a trajetória de Jover Teles. Através de alguns desses percursos, compreendi que não adiantava escolher uma das três categorias propostas por Philipe Lejeune (2005), tampouco optar por um dos paradigmas de Daniel Madelénat (1984), por uma das modalidades de François Dosse (2009) ou de Giovanni Levi (2008). Não se tratava de uma questão de "escolha". As dificuldades iniciais demonstraram que se tratava da necessidade de uma melhor definição sobre qual seria meu objeto de estudo, respeitando algumas tendências teóricas e metodológicas atualmente admitidas e debatidas na historiografia e na literatura em geral sobre o método biográfico. Além disso, algumas críticas realizadas por Giovanni Levi (2008) sobre as biografias ancoradas no contexto alertaram-me para inevitáveis incongruências. Segundo ele, o contexto é usado para "preencher as lacunas documentais" da biografia, sendo "frequentemente apresentado como algo rígido, coerente" e servindo como "pano de fundo imóvel para explicar a biografia" (LEVI, 2008, p. 176). Percebi que não era esse o meu objetivo. Não gostaria e nem poderia dar conta de uma categoria social ou de um coletivo através de um indivíduo, até por que minhas fontes de pesquisa não me dariam suporte para tal empreendimento. Quanto à abordagem biográfica, foi importante compreender, conforme afirma Levi, que “nenhum sistema normativo é suficientemente estruturado para eliminar qualquer possibilidade de escolha consciente, de manipulação ou de interpretação das regras, de negociação" (LEVI, 2008, p. 176). Desse modo, ao examinar a trajetória de vida de Manoel Jover Teles, busquei examinar alguns aspectos dos diferentes contextos políticos e culturais nos quais circulou, estando atento igualmente aos seus campos de oportunidades e a seus espaços de exercício de liberdade.
Outra percepção alterada nos bastidores da pesquisa que resultou na biografia de Manolo diz respeito ao recorte temporal dado à biografia. Hoje, acredito que o recorte temporal de uma pesquisa biográfica deve, no mínimo, estar localizado durante todo o período de vida do indivíduo biografado. Mesmo que o objetivo do pesquisador seja aprofundar algumas questões em determinado momento ou fase de uma história de vida, não se deve desconsiderar o percurso de existência do biografado em sua totalidade. Principalmente por causa da memória, o percurso de uma vida não acontece de forma linear e as informações sobre os eventos de uma determinada etapa da vida do sujeito podem vir a esclarecer outros momentos de sua trajetória, iluminando a biografia e, às vezes, reorientando o percurso da própria pesquisa.

Mesmo reconhecendo que a biografia é um gênero híbrido, a proposta de realização da biografia de Manoel Jover Teles enquadrou-se naquilo que poderíamos chamar de "biografia histórica". Entende-se por biografia histórica a perspectiva biográfica que busca articular narração e explicação, regulada pelas regras de pesquisa e de produção escrita comuns à área da História.

Conforme esclareceu Le Goff (1989, p. 48),

la biographie historique doit se faire, à un certain degree au moins, récit, narration d'une vie, elle s'articule autour de certains événements individuels ou collectives - une biographie non événementielle n'a pas de sens et comme elle doit être consacrée à un personnage sur lequel on possède suffisamment d'informations, de documents, elle a de bonnes chances d'être dédiée à un homme politique ou ayant des rapports avec la politique. ${ }^{6}$

6 "A biografia histórica deve ser feita, ao menos em certo grau, como uma narração, a narração de uma vida que se articula em alguns eventos individuais ou coletivos - uma biografia sem eventos não faz sentido e como tal deve ser dedicada a um personagem sobre o qual possuímos informações e documentos suficientes; ela tem boas chances de ser aplicada a um político ou a alguém que tenha relações com a política". (Tradução nossa) 
Se a biografia histórica deve ser realizada através de uma articulação entre a narração de uma vida em torno de seus eventos individuais ou coletivos, uma verdadeira biografia nesse sentido "est d'abord la vie d'un individu et la légitimité du genre historique passe par le respect de cet objectif : la présentation et l'explication d'une vie individuelle dans l'histoire" (LE GOFF, 1989, p. 49).' Dessa forma, encontrei um método biográfico que, partindo da história de vida de um indivíduo, aborda questões mais gerais relacionadas à época em que ele viveu, articulando a "história-narrativa" com a "história-problema".

\section{Biografia, micro-história, arquivos e fontes}

Até o momento, apresentei alguns elementos em relação ao primeiro desafio enfrentado por mim, nos bastidores da biografia de Manoel Jover Teles: compreender e/ou encontrar o tipo, o estilo, as especificidades e os principais cuidados da feitura de uma biografia no campo da História. A partir desse momento, apresentarei mais dois desafios. Um deles está relacionado às possíveis relações da biografia histórica com o exercício de microanálise, uma vez que me foi sugerido retirar da tese referências à inspiração que havia assumido em relação à perspectiva da micro-história. O outro, refere-se ao conjunto tão variado de fontes, arquivos e viagens que precisaram ser realizadas para me aproximar dos "fios" e dos "rastros" de Manolo.

Contrariamente ao que me foi sugerido, acredito que a biografia escrita por mim sobre Manoel Jover Teles resultou de uma umbilical inspiração nas leituras que realizei sobre mi-

7 Uma verdadeira biografia, nesse sentido, "é aquela na qual, primeiramente, a vida de um indivíduo e a legitimidade do gênero histórico passa por aquilo que diz respeito ao seu objetivo: a apresentação e a explicação de uma vida individual na história". (Tradução nossa) cro-história e suas relações com o gênero biográfico. Aliás, lembro-me de que não apenas eu pensava assim. Jordi Canal, professor da EHESS de Paris, que foi um dos integrantes da banca de defesa, comentou que "era evidente a influência da abordagem microanalítica" na biografia de Manolo.

A micro-história nasceu de um projeto e um movimento desenvolvidos a partir da década de 1970 por um grupo de historiadores italianos. Reunidos na revista "Quaderni Storici", Carlo Ginzburg e Giovanni Levi lançaram uma espécie de "reação, como uma tomada de posição frente a um certo estado [de crise] da história social" (REVEL, 1998, p. 16). Tratava-se de um contexto de crise mais geral das "concepções de ciência e dos modelos de um 'fazer científico' que não mais davam conta de compreender a complexidade do todo sem o exercício de uma análise mais qualitativa e exaustiva das partes" (SILVEIRA, 2010, p. 3). A rigor, a perspectiva da micro-história e da microanálise, segundo Carlo Ginzburg, implica em reduzir a escala de observação, isto é "transformar num livro aquilo que poderia ter sido uma simples nota de rodapé numa hipotética monografia sobre a reforma protestante no Friul" (2007, p. 264).

Em vários momentos, a biografia escrita sobre Manolo exercitou essa redução de escala. Esse exercício, conforme defendeu Ginzburg (1991, p. 178), “permite em muitos casos uma reconstituição [sic] do vivido impensável em outros tipos de historiografia", pois permite "indagar as estruturas invisiveis dentro das quais aquele vivido se articula". Assim, ao examinar a trajetória de vida de Jover Teles, busquei explicar alguns aspectos dos diferentes contextos sociais nos quais se inseriu e, de certa forma, que ele ajudou a produzir. Nesse sentido, tornou-se imperativo observar em sua trajetória seus campos de oportunidades e seus espaços de exercício 
de liberdade dentro dos sistemas normativos aos quais se imbricou.

Conforme destacou Henrique Espada Lima, a redução da escala de análise "tem um objetivo principal: lançar luz sobre as dimensões da atividade humana que, em uma análise menos microscópica, permaneceriam na obscuridade". Essa perspectiva, segundo ele, permite "revelar aspectos do problema pesquisado que seriam inacessiveis de outra forma" (LIMA FILHO, 1993, p. 3). Ao analisar a importância dos estudos biográficos para a micro-história, Lima ponderou:

Entretanto, a biografia no horizonte da 'microstoria' tem uma peculiaridade da qual não participa, por exemplo, a biografia francesa: enquanto na França o 'retorno' da biografia trouxe à luz especialmente trabalhos sobre grandes personagens como Pétain e São Luís, a primeira [italiana] irá voltar-se principalmente para figuras completamente desconhecidas que se tornam objeto e pretexto para biografias que têm como problemas, frequentemente, aspectos que transcendem largamente os horizontes individuais dos seus personagens. Como o moleiro Menocchio, objeto de um estudo biográfico e microhistórico através do qual Ginzburg explorou aspectos da cultura popular e suas relações com a cultura erudita. (LIMA FILHO, 1993, p. 3)

A bigrafia de Jover Teles, assim como defende a perspectiva micro-histórica, na medida em que partiu e preservou uma questão específica, individual, permitiu fazer questões mais gerais sobre os grupos e a sociedade nos quais ele esteve inserido. Assim, privilegiando como objeto a vida política do indivíduo biografado, analisando "os fios e os rastros" deixados por ele, foi possivel explicar detalhes da dissidência comunista brasileira da segunda metade do século XX, bem como lançar luz sobre questões relativas à concepção e aos papéis desempenhados pelas figuras da "traição" e do "traidor", especialmente na perspectiva da cultura política comunista. A biografia, na dire- ção da microanálise, "permitiria pensar [...] os próprios limites da liberdade do sujeito individual; de como que, nas lacunas e ambiguidades das regras sociais, os indivíduos manipulam e reinterpretam as normas", contribuindo "para gerar as mudanças sociais" (LIMA FILHO, 1993, p. 6).

Quando menciono a perspectiva da "microanálise", refiro-me, conforme Vainfas (2002, p. 111), “à descrição e interpretação de casos minúsculos e periféricos à luz de uma história geral". Uma análise que relacione o "micro" ao "macro" e vice-versa. Nessa perspectiva, vale lembrar o que salientou Roger Chartier, quando disse que, atualmente,

[...] o objeto da história [...] não são, ou não são mais as estruturas e os mecanismos que regulam, fora de qualquer controle subjetivo, as relações sociais, e sim as racionalidades e as estratégias acionadas pelas comunidades, as parentelas, as famílias, os indivíduos. (CHARTIER, 1994, p. 102)

Dessa forma, microanálise e biografia histórica se aproximam, na medida em que permitem registrar uma série de fatos significativos que seriam imperceptiveis e que, no entanto, puderam ser interpretados por sua inserção em contextos mais amplos.

Para que a história de Manolo não caísse em algo "relativamente sencillo" (ROJAS, 2000, p. 16), procurarei capturar e produzir uma biografia do personagem a partir de diferentes ângulos, "construindo-os não de uma maneira linear, coerente, estável, mas levando em conta suas hesitações, incertezas, incoerências e transformações" (SCHMIDT, 2000b, p. 199). Essa forma de construção, sem dúvida, foi um dos grandes desafios de sua biografia. De acordo com Schmidt (2004), esse cuidado na forma de construção da narrativa é um dos fatores que distancia essa perspectiva biográfica do modelo tradicional e ou sensacionalista - o que Pierre Bourdieu chamou de "ilu- 
são biográfica". Bourdieu entendeu trajetória como uma "série de posições sucessivamente ocupadas por um mesmo agente num espaço que é ele próprio um devir, estando sujeito a incessantes transformações" (1996, p. 189). Desse modo, alguns conceitos e contribuições críticas desse sociólogo também foram importantes para melhor enxergar o objeto de estudo e desenvolver os objetivos da investigação. A partir das suas ponderações, no conhecido texto “A ilusão biográfica" (BOURDIEU, 1996), buscou-se evitar uma ordenação dos fatos que compusessem uma sequência coerentemente lógica e linear dos acontecimentos da trajetória de Jover Teles.

Portanto, passados três anos de distanciamento da finalização de uma biografia histórica sobre Manolo, compreendo que existem sim algumas aproximações entre a biografia que se produziu e a perspectiva da microanálise. Outra questão que também pode ajudar a explicar a direção nessa perspectiva, além da redução da escala de análise em vários momentos da escrita, está relacionada à quantidade impressionante de documentos a que tive acesso durante a investigação. De modo geral, durante os anos em que pesquisei a vida de Manoel Jover Teles, fui levado a pesquisar em diferentes arquivos e fontes, espalhados em diferentes Estados brasileiros. Aliás, penso que em relação à produção de uma biografia histórica nessa perspectiva, o pesquisador deve buscar ter acesso a uma variedade de fontes documentais e bibliográficas. Escrever sobre uma vida nessa direção, exige disposição para juntar diferentes peças de um complexo quebra-cabeças. Trabalho semelhante ao de um detetive, o biógrafo, historiador ou não, precisa estar atento às redes, espaços, instituições e, também, aos rastros das chamadas "escritas de si" deixadas pelo biografado. É certo que nem sempre o pesquisador terá à sua disposição o corpus documental desejado.
No entanto, mesmo nesses casos, o trabalho é árduo pois exigirá, através de literatura e outros casos similares, a (re)construção dos contextos mais significativos da vida que se escreve e analisa. ${ }^{8}$

Fruto de uma pesquisa documental de quatro anos em acervos localizados nos Estados de Santa Catarina, São Paulo, Rio Grande do Sul e Rio de Janeiro, e de uma pesquisa bibliográfica realizada no Brasil e na França, a biografia de Manoel Jover Teles resultou da análise e do cruzamento de diferentes arquivos e fontes. No Arquivo Público do Estado do Rio de Janeiro e no Arquivo Público do Estado de São Paulo foram pesquisados periódicos e documentos produzidos por órgãos da repressão, especialmente interrogatórios, dossiês, inquéritos policiais, pedidos de busca e apreensão e correspondências. No Rio Grande do Sul, as fontes foram igualmente variadas. Dentre elas, pesquisou-se os discursos e apartes de Manoel Jover Teles quando fora deputado estadual, em 1947, na Assembleia Legislativa do Rio Grande do Sul, particularmente os pronunciamentos que apresentaram denúncias, críticas e outras informações sobre as minas de carvão de São Jerônimo. Foram utilizadas, ainda, algumas matérias jornalísticas do jornal Correio do Povo, com o intuito de contextualizar e cotejar os discursos de Jover Teles com as fontes orais (entrevistas com ex-mineiros contemporâneos ao biografado, familiares e pessoas da comunidade que o conheceram), bem como para tornar mais complexa a análise e a abordagem de seu cotidiano enquanto operário das minas de carvão. Para isso, a pesquisa nos acervos do setor da Memória Parlamentar da Assembleia e do setor de pesquisa do Museu de Comunicação Social Hipólito José da Costa foram imprescindiveis.

Da mesma forma, compôs o quebra-cabeças alguns registros de casas de detenção rela-

8 Ver, por exemplo, o belo trabalho de Yonissa Wadi (2009). 
tivos à prisão de mineiros, no Arquivo Histórico de Porto Alegre, pois Manoel Jover Teles teria sido preso junto com o pai e irmãos, quando todos trabalhavam como operários nas minas de carvão, bem como um processo da Justiça do Trabalho do Rio Grande do Sul, encontrado no Memorial da Justiça do Trabalho do Estado, no qual Jover Teles figura como parte reclamada pela Cia. de Mineração. No mesmo sentido, outra importante e distinta ação trabalhista pesquisada foi a movida pelo irmão de Jover Teles contra a mesma empresa, encontrada no acervo de processos judiciais do Arquivo Judicial Centralizado de Porto Alegre. Acervos digitais foram igualmente importantes, pois, através de algumas hemerotecas, foi possivel ter acesso a sequências mais completas e regulares de jornais vinculados aos partidos políticos nos quais Manolo teve militância, particularmente o PCB e o PC do B. Em Santa Catarina, Estado onde Jover viveu os últimos dez anos de sua vida, ele escreveu poemas e passou a integrar novas redes, onde alcançou destaque: entrou para a Academia Catarinense de Letras e Artes de Santa Catarina - ACLA-SC -, ocupando a cadeira de no 11, integrou o Grupo de Poetas Livres de Santa Catarina e a Associação dos Cronistas, Poetas e Contistas Catarinenses - ACPCC. Essas fontes, basicamente poemas e outros textos de Jover Teles publicados em periódicos locais e/ou arquivados no Grupo de Poetas Livres de Santa Catarina, compuseram um conjunto de documentos da "escrita de si", de caráter autobiográfico. Nos rastros seletivos da memória, seus poemas deixaram pistas a partir das quais é possível capturar as razões e sentimentos que ele usou para representar ou qualificar sua realidade e seu passado. Razões e sentimentos que, como registrou Sandra Pesavento (2007, p. 10), "expressam os sentidos que os homens, em cada momento de sua história, foram capazes de dar a si próprios e ao mundo". Através da poesia e de novas relações estabelecidas em Santa Catarina, Manolo conseguiu lidar com o estigma da traição. Enfim, o que gostaria de salientar é que, não raro, nos bastidores da pesquisa e da escrita sobre a vida de alguém, lidamos com uma variedade considerável de arquivos e fontes. Por serem distintos, tais documentos exigem do pesquisador, além de muita atenção e organização, uma postura rigorosa em relação aos cuidados metodológicos de análise, pois, frequentemente, devido à especificidade e particularidade da fonte e seu contexto de produção, será necessário utilizar diferentes lentes para sua leitura e problematização.

\section{Considerações Finais}

David Nasaw, professor de História Americana do Centro de Pós-Graduação da Universidade da cidade de Nova York, em um artigo intitulado "Historians and biography", salientou que existe certa ambivalência entre historiadores quanto ao gênero da biografia. "Enquanto a maioria certamente reconhece a biografia como um modo legítimo e respeitável do discurso histórico", disse ele, "muitos estão céticos quanto à capacidade da biografia em transmitir um tipo de interpretação analítica sofisticada do passado" (2009, p. 573). Penso que ele infelizmente esteja certo, pois não é dificil encontrar posicionamentos ambivalentes, especialmente daqueles que se intimidam com as demandas da biografia ou que criticam o gênero biográfico, seja por falta de compreensão teórico-metodológica, seja devido às inseguranças que os impedem de ver na escrita biográfica uma oportunidade para, como disse François Dosse, "avaliar o caráter ambivalente da epistemologia" (2009, p. 18) da própria História. Eu poderia citar como rápido exemplo as críticas de Sérgio da Costa Franco publicadas em Zero Hora, na ocasião do lançamento da biografia de João Goulart escrita por Jorge Ferreira (2011). Em seu texto, Franco 
conclui dizendo: "é valiosa a biografia produzida por Jorge Ferreira, mas apesar de sua extensão, ainda fica nos devendo muita coisa" (2012, s.p.). Por trás da avaliação pejorativa da ausência, também há, entre outras coisas, a ambivalência citada por David Nasaw (2009). Ou seja, por um lado, a biografia é "valiosa", por outro, "fica devendo muita coisa".

Gostaria de chamar a atenção para esse aspecto nessas considerações finais. Talvez, este seja outro importante desafio a considerar nos bastidores de uma pesquisa biográfica: estar ciente dos limites existentes à prática da biografia, pois ela sempre terá como resultado um trabalho inacabado. Como disse François Dosse, “o biógrafo sabe que jamais concluirá sua obra, não importa o número de fontes que consiga exumar" (2009, p. 14). Ou, nas palavras de Paul Ricoeur, "escrever a vida é uma outra história. Uma história inacabada" (apud DOSSE, 2009, p. 11). E por que esta consciência? Na objetividade da vida de alguém, os caminhos

\section{Referências}

BORGES, Vavy Pacheco. Desafios da memória e da biografia: Gabrielle Brune-Sieler, uma vida (18741940). In: BRESCIANI, Stella; NAXARA, Márcia. (Orgs.). Memória e (res)sentimento: indagações sobre uma questão sensível. 2. ed. Campinas, SP: Editora Unicamp, 2004. p. 283-308.

BORGES, Vavy Pacheco. Grandezas e misérias da biografia. In: PINSKY, Carla Bessanezi. (Org.). Fontes Históricas. 2. ed. São Paulo: Contexto, 2006. p. 203233.

BOURDIEU, Pierre. A ilusão biográfica. In: AMADO, Janaína; FERREIRA, Marieta de Moraes. (Orgs.). Usos e abusos da história oral. Rio de Janeiro: Editora da FGV, 1996. p. 183-192.

CHARTIER, Roger. A história hoje: dúvidas, desafios, propostas. Estudos históricos, Rio de Janeiro, v. 7, n. 13, p. 97-113, 1994. vão se desdobrando de forma dinâmica, com uma lógica e uma coerência que é dada pelo próprio sujeito que, ao viver, se constitui e constitui sua história. Ao pesquisador, entretanto, é posto o desafio de decifrar essa lógica, de dissecar essa trajetória, de seccionar os movimentos articulados e simultâneos em recortes inanimados de vida narrada e descrita. Se a vida é um arranjo múltiplo e multidimensional, complexo como um tecido, a pesquisa sobre uma vida é um exercício de desaceleração que se efetiva em escolhas e eleições que o pesquisador é obrigado a fazer. Cada fio que se toma corresponde a uma dimensão, cada linha narrativa dá conta de abordar pouco mais do que um aspecto da multiplicidade que é a vida do sujeito. Nesse sentido, sempre há de faltar (à vida recontada) a parcela de vitalidade que a vida vivida contém. Mas essa é uma condição inevitável ao pesquisador. Esse é um dos limites que se impõem ao pesquisador e ao biógrafo.

MADELÉNAT, Daniel. La biographie. Paris: PUF, 1984.

DEL PRIORE, Mary. Biografia: quando o indivíduo encontra a história. Topoi, v. 10, n. 19, p. 7-16, jul./dez. 2009.

DOSSE, François. 0 desafio biográfico: escrever uma vida. Tradução Gilson César Cardoso de Souza. São Paulo: Editora da Universidade de São Paulo, 2009.

FERREIRA, Jorge. João Goulart: uma biografia. Rio de Janeiro: Civilização Brasileira, 2011.

FRANCO, Sérgio da Costa. Biografia de João Goulart. Zero Hora, 28 de agosto de 2012, s.p.

GINZBURG, Carlo. A micro-história e outros ensaios. Tradução de António Narino. Lisboa: Difel; Rio de Janeiro: Bertrand Brasil, 1991.

GINZBURG, Carlo. 0 fio e os rastros: verdadeiro, 
falso, fictício. Tradução de Rosa Freire d'Aguiar e Eduardo Brandão. São Paulo: Cia. das Letras, 2007.

GINZBURG, Carlo. 0 queijo e os vermes. Tradução de Maria Betânia Amoroso. São Paulo: Cia. das Letras, 2006. [1a edição 1976].

LE GOFF, Jacques. Comment écrire une biographie historique aujourd'hui? Le Débat, n. 54, p. 48-53, mars./avril. 1989.

LEJEUNE, Philippe. Signes de vie: le pacte autobiographique. Paris: Seiul, 2005.

LEVI, Giovanni. Usos da biografia. In: AMADO, Janaína; FERREIRA, Marieta de Moraes (Orgs.). Usos e abusos da história oral. Rio de Janeiro: Editora da FGV, 2008. p. 167-182.

LIMA FILHO, Henrique Espada R. Biografia e Microstoria: o uso da biografia na historiografia italiana contemporânea. Cadernos, Centro de Filosofia e Ciências Humanas da UFPA, Belém, v. 12, n. 1/2, p. 1-11, jan./dez., 1993.

LORIGA, Sabina. A biografia como problema. In: REVEL, Jacques. (Org.). Jogos de escalas. A experiência da microanálise. Rio de Janeiro: Editora da Fundação Getúlio Vargas, 1998. p. 225-250.

LORIGA, Sabina. $\mathbf{O}$ pequeno X. Da biografia à história. Tradução de Fernando Scheibe. Belo Horizonte: Autêntica, 2011.

NASAW, David. Historians and biography. American Historical Review, v. 114, n. 3, p. 573-578, june 2009. Disponivel em: <http://ahr.oxfordjournals.org/content/114/3/573.full.pdf>. Acesso em: 13 set. 2016.

PESAVENTO, Sandra. Sensibilidades: escrita e leitura da alma. In: PESAVENTO, Sandra J.; LANGUE, Frédérique. Sensibilidades na história: memórias singulares e identidades sociais. Porto Alegre: Editora da UFRGS, 2007. p. 23-42.

REVEL, Jacques. Microanálise e construção do social. In: Jogos de escalas: a experiência da microanálise. Rio de Janeiro: Fundação Getúlio Vargas Editora, 1998. p. 15-38.

ROJAS, Carlos Antonio Aguirre. La biografia como género historiográfico: algunas reflexiones sobre sus posibilidades actuales. In: SCHMIDT, Benito. (Org.). O biográfico: perspectivas interdisciplinares. Santa Cruz do Sul: Edunisc, 2000. p. 9-48.

SCHMIDT, Benito. (Org.). o biógrafico: perspectivas interdisciplinares. Santa Cruz do Sul: Edunisc, 2000b.

SCHMIDT, Benito Bisso. Biografia: um gênero de fronteira entre a história e a literatura. In: RAGO, Margareth; GIMENES, Renato Aloizio de Oliveira. (Orgs.). Narrar o passado, repensar a história. Campinas, SP: Unicamp; IFCH, 2000a. p. 191-202.

SCHMIDT, Benito Bisso. Biografias históricas: o que há de novo? In: SEBRIAN, Raphael Nunes Nicoletti; FERREIRA, Ricardo Alexandre; ANHEZINI, Karina; PIRES, Ariel José. (Orgs.). Leituras do passado. Campinas, SP: Pontes, 2009. p. 73-82.

SCHMIDT, Benito Bisso. Relações perigosas: história e biografia. Registro de palestra proferida no "Encontros Transdisciplinares (I). (AUTO)BIOGRAFIA(S)". Porto Alegre, Universidade Federal do Rio Grande do Sul, Sala Pantheon do IFCH/UFRGS Campus do Vale, 6 de junho de 2011.

SCHMIDT, Benito Bisso. Em busca da terra da promissão: a história de dois líderes socialistas. Porto Alegre: Palmarinca, 2004.

SILVEIRA, Éder da Silva. Estudo de caso e micro-história: distanciamentos, características e aproximações. Revista História em Reflexão, Dourados, UFGD, v. 4, n. 8, p. 1-10, jul./dez. 2010.

SILVEIRA, Éder da Silva. Por que ele? Educação, traição e dissidência comunista na trajetória de Manoel Jover Teles, o "Manolo". São Paulo: Paco Editorial, 2016.

VAINFAS, Ronaldo. Os protagonistas anônimos da história: micro-história. Rio de Janeiro: Editora Campus, 2002.

WADI, Yonissa Marmitt. A história de Pierina. Subjetividade, crime e loucura. Uberlândia, EDUFU, 2009.

Recebido em: 26.09.2016

Aprovado em: 25.11..2016 
Éder da Silva Silveira é professor pesquisador do Programa de Pós-Graduação em Educação e do Departamento de História e Geografia da Universidade de Santa Cruz do Sul - Unisc. Grupo de pesquisa: Educação, Trabalho e Emancipação. Doutor em História pela Universidade do Vale do Rio dos Sinos - Unisinos; mestre e pós-doutor em Educação pela PUC-RS.

Av. Independência, 2293, Bairro: Universitário, CEP: 96815-900, Santa Cruz do Sul - RS/ Brasil, Bloco 5 - Sala 506 (Departamento de História e Geografia).

e-mail: eders@unisc.br. 